\title{
Prediksi Kelulusan Mahasiswa Dalam Memilih Program Magister Menggunakan Algoritma $K-N N$
}

\author{
Aldo Sabathos Mananta ${ }^{1}$, Green Arther Sandag ${ }^{2}$ \\ e-mail: ${ }^{1}$ s21610010@ student.unklab.ac.id, ${ }^{2}$ greensandag@unklab.ac.id \\ ${ }^{1}$ Program Studi Sistem Informasi, ${ }^{2}$ Program Studi Informatika, Universitas Klabat, Airmadidi
}

\begin{abstract}
Abstrak
Kinerja akademik siswa didasarkan pada berbagai faktor seperti variabel pribadi, sosial, psikologis, dan lingkungan lainnya. Banyaknya jumlah data yang dimiliki oleh pihak universitas mengenai mahasiswa lulusan mereka dapat membantu dalam proses pengambilan keputusan ke jenjang pendidikan yang lebih tinggi. Data akademik mahasiswa dapat diolah untuk membantu pengambilan keputusan dalam penentuan masuk ke jenjang perguruan tinggi selanjutnya. Untuk melakukan proses pengolahan data tersebut di butuhkan metode data mining yaitu klasifikasi. Aspek yang dilihat yaitu dari sisi accuracy, precision dan recall. Software yang digunakan untuk mengetahui kinerja dari algoritma tersebut adalah Rapid Miner Studio versi 9.2. Hasil pengujian menunjukkan bahwa algoritma $K-N N$ dengan menggunakan independent test memiliki accuracy terbaik yaitu sebesar $96.25 \%$, precision $98.08 \%$, dan recall $70.00 \%$. Sedangkan pada test yang menggunakan cross-validation, algoritma $K-N N$ juga memiliki accuracy terbaik yaitu sebesar $91.88 \%$, precision 81.29, dan recall $61.15 \%$
\end{abstract}

Kata kunci : Prediksi, Kelulusan Mahasiswa, K-NN

\section{Pendahuluan}

Seiring dengan perkembangan zaman, perkembangan teknologi informasi telah berkembang dengan sangat pesat. Banyak data berupa informasi dari berbagai bidang yang dapat dihasilkan dari teknologi informasi yang canggih, baik itu dari bidang ekonomi, industri, ilmu dan teknologi, serta dari berbagai bidang lainnya. Dalam dunia pendidikan teknologi informasi dapat menghasilkan data yang berlimpah berupa data dari masing-masing siswa maupun individu lainnya. Dalam dunia pendidikan terutama pada perguruan tinggi, penerapan teknologi informasi dalam membantu institusi pendidikan untuk melakukan pengolahan data sangatlah penting dikarenakan data mahasiswa tiap tahun semakin bertambah, dapat menghasilkan informasi yang berlimpah setiap tahunnya berupa jumlah kelulusan, profil, dan hasil akademik mahasiswa selama menempuh kegiatan akademik pada perguruan tinggi tersebut ${ }^{[1]}$.

Dengan adanya teknologi informasi, data yang berlimpah dapat diolah agar berguna bagi pihak universitas [2]. Pentingnya pengolahan data mahasiswa bagi pihak universitas untuk mengetahui informasi penting berupa pengetahuan yang baru, seperti informasi yang terkait mengenai profil dan informasi akademik dari mahasiswa tersebut. Salah satu standar mutu dari pendidikan tinggi adalah berdasarkan pada organisasi kemahasiswaan yang artinya perbandingan mahasiswa dan dosen. Harapan untuk pendidikan tinggi adalah mampu menghasilkan alumni dengan kualitas tinggi. Salah satu kriteria untuk kualitas tinggi dapat dijelaskan dengan status kelulusan siswa di sebuah institusi ${ }^{[3]}$.

Kinerja akademik siswa didasarkan pada berbagai faktor seperti variabel pribadi, sosial, psikologis, dan lingkungan lainnya. Penggunaan data mining merupakan metode yang sangat berguna untuk mencapai tujuan ini. Teknik data mining digunakan untuk pengoperasian dalam data yang besar, bertujuan untuk menemukan pola dan hubungan yang tersembunyi dalam membantu pengambilan keputusan ${ }^{[4]}$. Banyaknya jumlah data yang dimiliki oleh pihak universitas mengenai mahasiswa lulusan mereka dapat membantu dalam proses pengambilan keputusan ke jenjang pendidikan yang lebih tinggi. Data akademik mahasiswa dapat 
Table 1. Dataset

\begin{tabular}{|l|l|l|}
\hline \multicolumn{1}{|c|}{ Attributes } & \multicolumn{1}{|c|}{ Details } & \multicolumn{1}{|c|}{ Value } \\
\hline Serial No & Nomor serial dari setiap rows dalam dataset. & Integer \\
\hline GRE Score & $\begin{array}{l}\text { GRE (Graduate Record Examination) adalah nilai ujian standar yang } \\
\text { seringkali diperlukan untuk masuk ke program pascasarjana secara } \\
\text { global. }\end{array}$ & Integer \\
\hline TOEFL Score & $\begin{array}{l}\text { TOEFL (Test of English as a Foreign Language) merupakan nilai test } \\
\text { keahlian yang digunakan untuk mengukur kemampuan berbahasa } \\
\text { inggris seseorang. }\end{array}$ & Integer \\
\hline University Rating & Tingkatan atau peringkat dari sebuah universitas. & Integer \\
\hline SOP & $\begin{array}{l}\text { SOP (Statement of Purpose) adalah jenis esai yang ditulis ketika } \\
\text { melamar ke program tertentu dalam hal ini program pascasarjana di } \\
\text { universitas tertentu. }\end{array}$ & Float \\
\hline LOR & $\begin{array}{l}\text { LOR (Letter of Recommendation) juga merupakan jenis kertas lain } \\
\text { yang ditulis saat melamar ke universitas tertentu. }\end{array}$ & Float \\
\hline CGPA & $\begin{array}{l}\text { CGPA (Cumulative Grade Points Average) adalah nilai mahasiswa } \\
\text { yang diperoleh di semua mata pelajaran. }\end{array}$ & Float \\
\hline Research & $\begin{array}{l}\text { Merupakan penelitian untuk mencari tahu berapa banyak lulusan } \\
\text { yang memiliki pengalaman penelitian. }\end{array}$ & Integer \\
\hline Chance of Admit & $\begin{array}{l}\text { Merupakan kemungkinan atau peluang mahasiswa diterima di suatu } \\
\text { universitas. }\end{array}$ & Float \\
\hline
\end{tabular}

diolah untuk membantu pengambilan keputusan dalam penentuan masuk ke jenjang perguruan tinggi selanjutnya. Untuk melakukan proses pengolahan data tersebut di butuhkan metode data mining yaitu klasifikasi. Klasifikasi merupakan metode yang di gunakan untuk membangun model prediksi. Sebagian besar peneliti menggunakan klasifikasi untuk memprediksi kinerja siswa ${ }^{[5]}$.

Dalam penelitian kali ini algoritma $K-N N$ digunakan sebagai acuan untuk menentukan tingkat peluang kelulusan mahasiswa dalam menentukan universitas yang dia pilih. Dasar penentuan mahasiswa tersebut untuk lulus adalah GRE Scores, TOEFL Scores, University Rating, Statement of Purpose, Letter of Recommendation Strength, Undergraduate CGPA, Research Experience, dan Chance of Admit [6].

Penelitian sebelumya oleh kamagi yaitu implementasi data mining dengan algoritma c4.5 untuk memprediksi tingkat kelulusan mahasiswa mendapatkan hasil akurasi dari prediksi kelulusan sebesar $87,5 \%{ }^{[7]}$. Kemudian pada penelitian oleh hastuti yang analisis komparasi algoritma klasifikasi data mining untuk prediksi mahasiswa non aktif yang menggunakan perbandingan algoritma logistic regression, decision tree, naïve bayes, dan neural network mendapatkan hasil bahwa algoritma decision tree memiliki akurasi terbaik yaitu sebesar 95,29\% ${ }^{[8]}$. Penelitian terkait lainnya juga oleh ryan yang berjudul prediksi kelulusan mahasiswa berdasarkan kinerja akademik menggunakan pendekatan data mining pada program studi sistem informasi fakultas ilmu computer universitas brawijaya ${ }^{[9]}$.

Kami menggunakan algoritma k-nearest neighbor $(K-N N)$ karena algoritma ini memiliki tingkat akurasi yang tinggi. Tujuan dari penelitian ini adalah untuk mengetahui peluang lulus atau tidaknya mahasiswa dalam menentukan universitas pilihannya. Manfaat dari penelitian ini adalah untuk memberikan informasi kepada mahasiswa dalam menentukan universitas yang akan dia pilih.

\section{Metode Penelitian}

Data yang digunakan pada penelitian ini adalah Graduate Admission Dataset yang dapat di akses dari Kaggle ${ }^{[10]}$. Dataset ini memiliki 400 rows, dan 9 attributes yang dijelaskan di Tabel 1.

Design Penelitian seperti pada Gambar 1 memperlihatkan proses Prediksi Peluang Kelulusan Mahasiswa Dalam Memilih Universitas. Proses pertama adalah mengambil Graduate Admission Dataset yang diambil dari Kaggle, dilanjutkan dengan data 
processing yang akan mengolah data untuk mendapatkan final dataset. Kemudian final dataset dibagi menjadi $80 \%$ training dan $20 \%$ testing. Penelitian ini menggunakan $K$-Fold Cross Validation sebelum melakukan modelling. Selanjutnya data di proses menggunakan algoritma k-nearest neighbor $(K-N N)$, yang kemudian akan dibuat modelnya dan dievaluasi.

Data preprocessing dibagi menjadi 2 bagian, yaitu data cleaning dan data reduction. Data cleaning adalah proses pembersihan data incomplete pada attribute di dataset untuk membuat data menjadi lebih konsisten. Sedangkan, data reduction adalah proses untuk menghapus data pada attribute yang kurang dominan sehingga data bisa dikurangi, namun tetap menghasilkan data yang akurat. Jadi data target dan independent akan dipisahkan sebagai $\mathrm{X}$ dan $\mathrm{Y}$, lalu data akan dibagi menjadi train dan set tes dengan ukuran set tes $20 \%$. Kemudian pemindaian fitur akan dilakukan pada fitur independent untuk melakukan standarisasi.

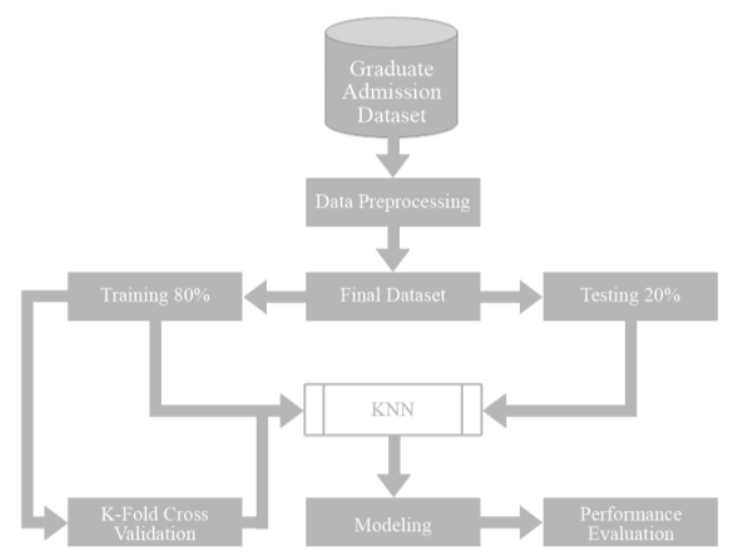

Gambar 1. Arsitektur untuk Prediksi Peluang

Kelulusan Mahasiswa Dalam Memilih Universitas

Setelah data telah dibagi menjadi $80 \%$ data training dan $20 \%$ data testing, maka akan dilakukan $K$-Fold Cross Validation pada data training. Cross Validation adalah teknik untuk mengevaluasi model dengan cara mempartisi sampel asli ke dalam training set untuk melatih model, dan test set untuk mengevaluasi model. Dalam K-Fold Cross Validation, sampel asli secara acak dipartisi dalam $k$ equal size subsample. Dari subsample $\mathrm{k}$, satu subsample akan digunakan sebagai testing data dan sisanya akan menjadi training data. Proses cross validation akan diulang sebanyak k kali (kelipatan), dengan masing masing dari subsample $\mathrm{k}$ digunakan sekali sebagai validation data ${ }^{[11]}$. Pada Gambar 2 menunjukkan proses $K$-Fold Cross Validation, data dibagi menjadi 9 partisi dan akan diuji sebanyak 9 kali sebelum dibuat modelnya.

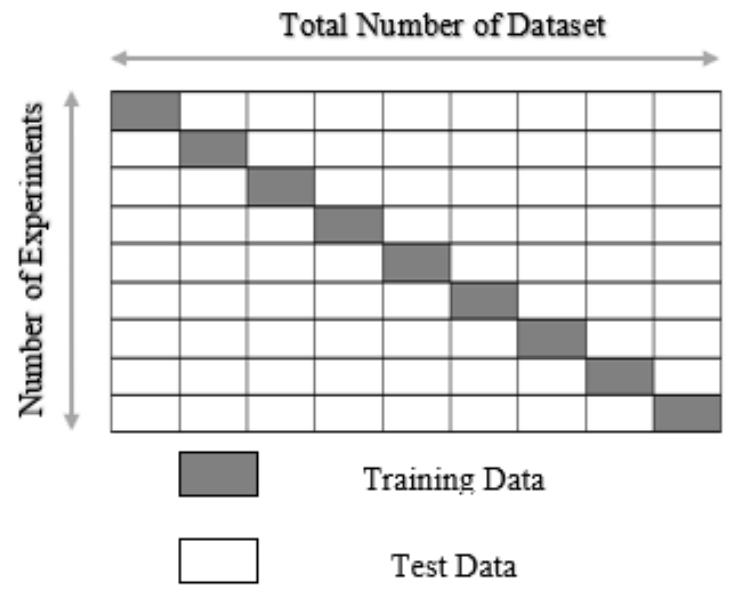

Gambar 2. K-Fold Cross Validation

Setelah proses K-Fold Cross Validation selanjutnya data akan diproses dengan menggunakan algoritma $K-N N$. Algoritma $K-N N$ adalah metode untuk klasifikasi objek berdasarkan training examples yang terdekat. $K-N N$ adalah instance-based learning atau disebut juga lazy learning, karena fungsinya hanya didekati secara local dan semua perhitungan ditunda hingga proses klasifikasi. $K$ - $N N$ adalah teknik klasifikasi yang paling sederhana ketika tidak ada pengetahuan tentang distribusi data ${ }^{[12]}$. Jarak dalam $K-N N$ dihitung menggunakan Euclidean Distance dengan rumus :

$$
d(x, y)=\sqrt{\sum_{i=1}^{n}(x i-y i)^{2}},
$$

Keterangan:
d : Jarak
i : Jumlah data
$\mathrm{n}$ : Banyaknya data
$\mathrm{x}$ : Titik awal
y: Titik akhir 
Setelah pembuatan model maka langkah selanjutnya adalah melakukan evaluasi

berpengaruh ${ }^{[14]}$. Penulis menggunakan metode information gain ratio untuk

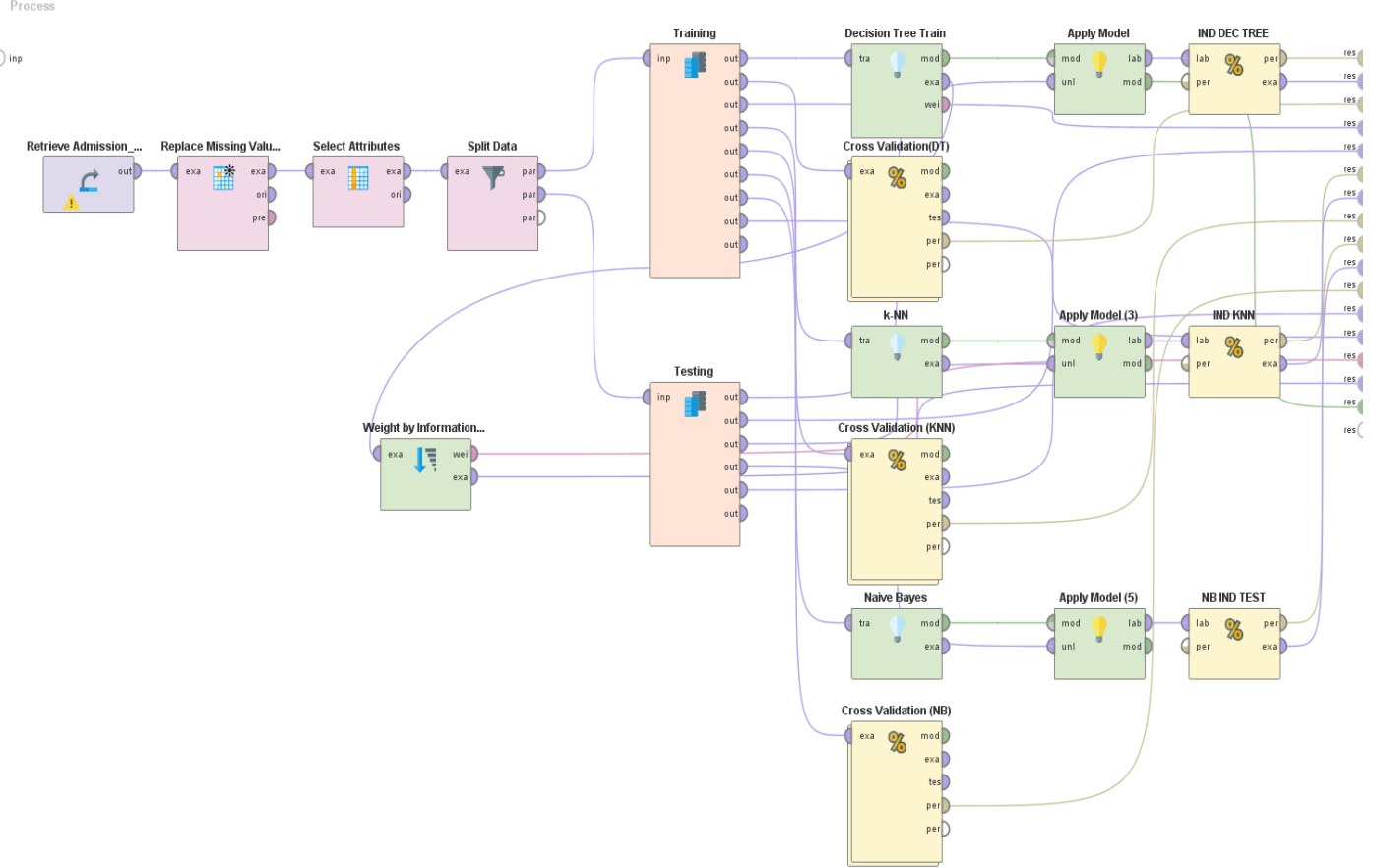

Gambar 3. Process K-Nearest Neighbor

dengan performance evaluation. Performance evaluation berguna untuk menguji performa dari classifier. Recall, precision, dan accuracy. Recall adalah kumpulan data positif yang diklasifikasikan dengan benar sebagai data positif. Precision adalah kumpulan data yang diklasifikasikan sebagai positif yang benar - benar positif. Accuracy adalah ketepatan klasifikasi data ${ }^{[13]}$.

Berikut ini adalah rumus recall, precision, dan accuracy dalam performance evaluation:

Recall $=(T P /(T P+F N))$,

Precision $=(T P /(T P+F P)$,

Accuracy $=(T P+T N) /$

$(T P+T N+F P+F N)$,

Keterangan :

TP : Nilai true positive

: Nilai true negative

$\mathrm{P} \quad$ : Jumlah data positive

FP

: Nilai false positive

$\mathrm{N} \quad$ : Jumlah data negative

FN

: Nilai false negative

Metode feature important memegang peran penting dalam memilih attribute yang siginifikan, melalui penghapusan attribute yang tidak relevan, dan oleh karena itu dapat digunakan untuk identifikasi attribute yang menentukan berapa besar pengaruh suatu attribute dalam dataset. Machine learning information gain dapat digunakan untuk membuat peringkat dari attributes.

Attributes yang memiliki information gain yang tinggi harus diberi peringkat lebih tinggi daripada attributes yang lain karena lebih berpengaruh dalam mengklasifikasikan data $^{[15]}$. Berikut ini adalah rumus dalam information gain:

$$
I G(A)=H(S)-\sum \frac{S i}{s} H(S i)
$$

Keterangan:

$\mathrm{H}(\mathrm{S}) \quad$ : Entropi dari dataset

$\mathrm{H}(\mathrm{Si}) \quad$ : Entropi dari i subset yang dihasilkan oleh partisi $\mathrm{S}$
A : Atribut dalam dataset 


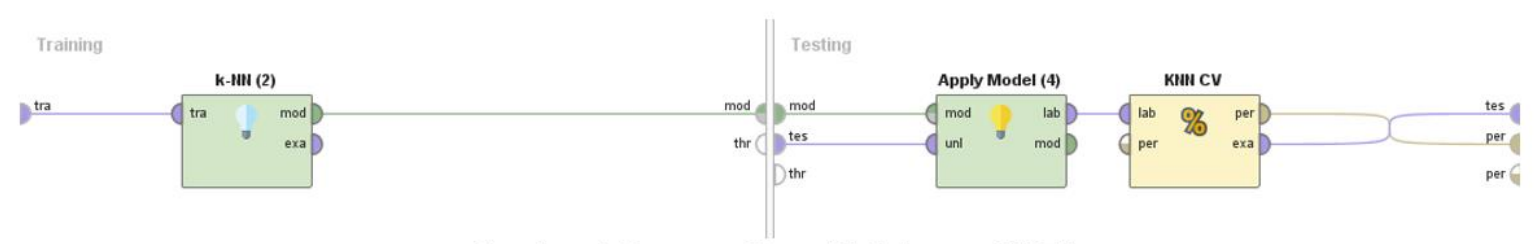

Gambar 4 Process Cross Validation K-NN

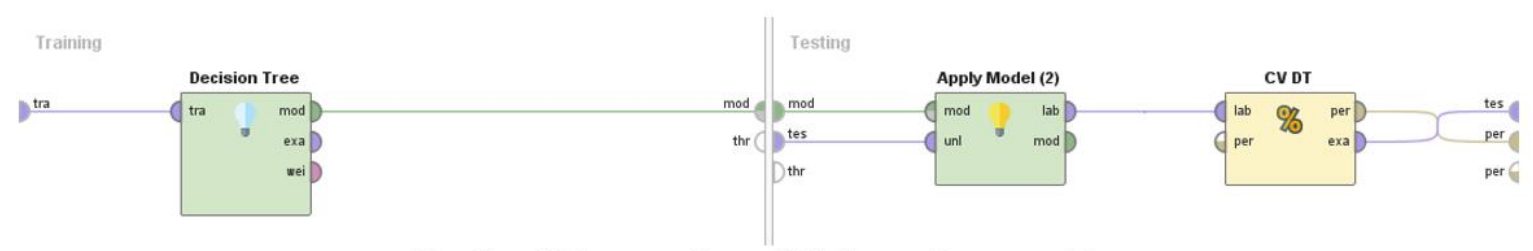

Gambar 5 Process Cross Validation Decision Tree

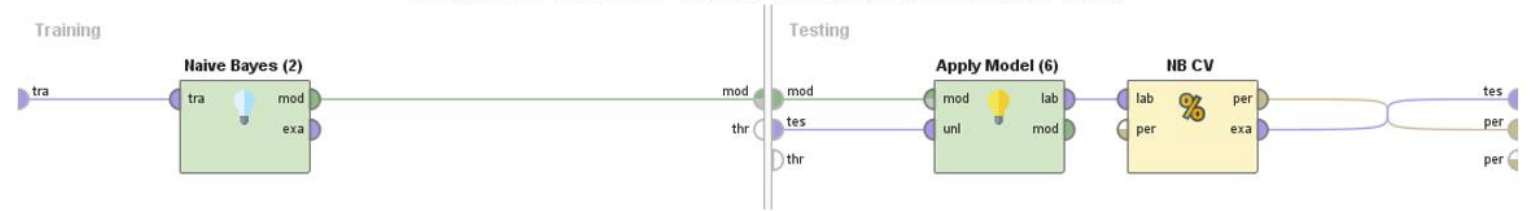

Gambar 6 Process Cross Validation Decision Tree

\section{Hasil dan Pembahasan}

Pada bagian ini penulis melakukan analisa terhadap graduate admission prediction menggunakan algoritma $k$-nearest neighbor $(K-N N)$. Gambar 3, 4, 5, dan 6 adalah use case proses pembuatan model dengan menggunakan algoritma KNN pada software Rapidminer.

Berdasarkan Gambar 7 dapat disimpulkan bahwa attribute $C G P A$ adalah attribute yang paling berpengaruh dalam memprediksi graduate admission dengan hasil weight 0.154. Sedangkan, attribute lain memiliki hasil yaitu Research 0.034, SOP 0.048, University Rating 0.052, LOR 0.075, TOEFL Score 0.103, dan GRE Score 0.097.

Table 2 menunjukkan hasil akurasi performance evaluation menggunakan K-Fold Cross Validation. Dari hasil yang telah didapat dengan menggunakan algoritma $k$ nearest neighbor (K-NN), didapati accuracy sebesar $91.88 \%$, precision $81.29 \%$, dan recall $61.15 \%$.
Tabel 2 Hasil Perbandingan Algoritma Dengan Menggunakan K-Fold Cross Validation

\begin{tabular}{|l|c|c|c|c|}
\hline Algoritma & $\begin{array}{c}\text { Accuracy } \\
(\%)\end{array}$ & $\begin{array}{c}\text { Precision } \\
(\%)\end{array}$ & $\begin{array}{c}\text { Recall } \\
(\%)\end{array}$ & $\begin{array}{c}\text { Error } \\
(\%)\end{array}$ \\
\hline K-NN & $91.88 \%$ & $81.29 \%$ & $61.15 \%$ & $8.13 \%$ \\
\hline $\begin{array}{l}\text { Decision } \\
\text { Tree }\end{array}$ & $91.56 \%$ & $75.79 \%$ & $66.95 \%$ & $8.44 \%$ \\
\hline $\begin{array}{l}\text { Naïve } \\
\text { Bayes }\end{array}$ & $85.00 \%$ & $67.00 \%$ & $82.76 \%$ & $15.0 \%$ \\
\hline
\end{tabular}

Tabel 3 menunjukkan hasil akurasi performance evaluation independent test. Dengan menggunakan algoritma $k$-nearest neighbor $(K-N N)$, didapati accuracy sebesar $96.25 \%$, precision $98.08 \%$, dan recall $70.00 \%$.

Tabel 3 Hasil Perbandingan Algoritma Dengan Menggunakan Independent Test

\begin{tabular}{|l|c|c|c|c|}
\hline Algoritma & $\begin{array}{c}\text { Accuracy } \\
(\%)\end{array}$ & $\begin{array}{c}\text { Precision } \\
(\%)\end{array}$ & $\begin{array}{c}\text { Recall } \\
(\%)\end{array}$ & $\begin{array}{c}\text { Error } \\
(\%)\end{array}$ \\
\hline K-NN & $96.25 \%$ & $98.08 \%$ & $70.00 \%$ & $3.75 \%$ \\
\hline $\begin{array}{l}\text { Decision } \\
\text { Tree }\end{array}$ & $92.50 \%$ & $70.06 \%$ & $77.33 \%$ & $7.50 \%$ \\
\hline $\begin{array}{l}\text { Naïve } \\
\text { Bayes }\end{array}$ & $82.50 \%$ & $63.16 \%$ & $90.67 \%$ & $17.50 \%$ \\
\hline
\end{tabular}

Tabel 4 menunjukan hasil perbandingan menggunakan algoritma $K-N N$ dengan membandingkan $K-5, K-10, K-15, K-20$, dan $K-100$. Algoritma $K-N N$ Cross Validation menggunakan $K$-20 merupakan $k$ optimal karena memiliki nilai accuracy yang tinggi dibandingkan dengan yang lain. 
Tabel 4 Hasil Perbandingan Algoritma K-NN Menggunakan Cross Validation

\begin{tabular}{|l|l|l|l|l|}
\hline K level & $\begin{array}{c}\text { Accuracy } \\
(\%)\end{array}$ & $\begin{array}{c}\text { Precision } \\
(\%)\end{array}$ & $\begin{array}{c}\text { Recall } \\
(\%)\end{array}$ & $\begin{array}{c}\text { Error } \\
(\%)\end{array}$ \\
\hline K-5 & $90.94 \%$ & $73.01 \%$ & $63.62 \%$ & $9.06 \%$ \\
\hline K-10 & $91.56 \%$ & $77.19 \%$ & $62.47 \%$ & $8.44 \%$ \\
\hline K-15 & $91.56 \%$ & $79.47 \%$ & $59.48 \%$ & $8.44 \%$ \\
\hline K-20 & $91.88 \%$ & $81.29 \%$ & $61.15 \%$ & $8.13 \%$ \\
\hline K-100 & $90.62 \%$ & $45.31 \%$ & $50.00 \%$ & $9.38 \%$ \\
\hline
\end{tabular}

Tabel 5 menunjukan hasil perbandingan menggunakan algoritma $K-N N$ dengan membandingkan $K-5, K-10, K-15, K-20$, dan $K$-100. Algoritma $K$-NN Independent Test menggunakan $K-5, K-10, K-15$, dan $K-20$ merupakan $k$ optimal karena memiliki nilai accuracy yang tinggi dibandingkan dengan $K-100$.

Tabel 5 Hasil Perbandingan Algoritma K-NN Menggunakan Independent Test

\begin{tabular}{|l|l|l|l|l|}
\hline \multicolumn{1}{|c|}{ K level } & $\begin{array}{c}\text { Accuracy } \\
(\%)\end{array}$ & $\begin{array}{c}\text { Precision } \\
(\%)\end{array}$ & $\begin{array}{c}\text { Recall } \\
(\%)\end{array}$ & $\begin{array}{c}\text { Error } \\
(\%)\end{array}$ \\
\hline K-5 & $96.25 \%$ & $98.08 \%$ & $70.00 \%$ & $3.75 \%$ \\
\hline K-10 & $96.25 \%$ & $98.08 \%$ & $70.00 \%$ & $3.75 \%$ \\
\hline K-15 & $96.25 \%$ & $98.08 \%$ & $70.00 \%$ & $3.75 \%$ \\
\hline K-20 & $96.25 \%$ & $98.08 \%$ & $70.00 \%$ & $3.75 \%$ \\
\hline K-100 & $93.75 \%$ & $46.88 \%$ & $50.00 \%$ & $6.25 \%$ \\
\hline
\end{tabular}

\section{Kesimpulan}

Dari ketiga algoritma yang telah dievaluasi yaitu K-Nearest Neighbor, Decision Tree, dan Naïve Bayes, untuk memprediksi graduate admission dapat disimpulkan bahwa algoritma $K-N N$ memiliki hasil yang paling baik diantara algoritma yang lain dengan accuracy sebesar $96.25 \%$, precision $98.08 \%$, dan recall 70.00 untuk independent test sedangkan untuk hasil test yang menggunakan cross-validation memiliki accuracy sebesar $91.88 \%$, precision $81.29 \%$, dan recall $61.15 \%$. Untuk kedepannya diharapkan model ini dapat berguna untuk pembuatan aplikasi prediksi graduate admission, dan untuk penelitian selanjutnya diharapkan peneliti dapat menggunakan metode dan algoritma

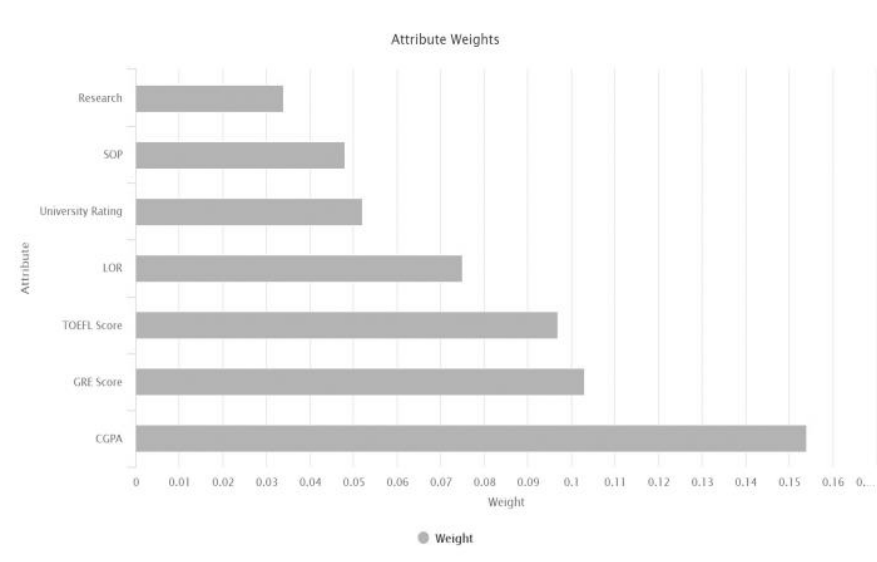

Gambar 7 Hasil Feature Importance

lain agar dapat memaksimalkan performance dan mengurangi nilai error dalam pemodeling.

\section{Daftar Pustaka}

[1] Nugroho, Y.S., "Data Mining Menggunakan Algoritma Naïve Bayes," UDiNus Repository, pp. 1-11, 2014.

[2] Ong, J.O., "Implementasi Algoritma K-Means Clustering Untuk Menentukan Strategi Marketing President University," Jurnal Ilmiah Teknik Industri, vol. 12, no. 1, pp. 1013, 2013.

[3] Kesumawati, A., "Implementation Naïve Bayes Algorithm for Student Classification Based on Graduation Status," International Journal of Applied Business and Information Systems, vol. 1, no. 2, pp. 6-12, 2017.

[4] Bhardwaj, B. K. dan Pal, S. , "Data Mining: A prediction for performance improvement using classification," International Journal of Computer Science and Information Security, vol. 9, no. 4, pp. 1-5, 2011.

[5] Mokhtar, M., Nawang, H. dan Shamsuddin, S. N. W., "Analysis On Students Permormance Using Naive Bayes Classifier," Journal of Theoretical and Applied Information Technology, vol. 95, no. 16, pp. 39934000, 2017.

[6] Acharya, M. S., "Kaggle," [Online]. Available:

https://www.kaggle.com/mohansachar ya/graduate-admissions. [Diakses 24 April 2020]. 
[7] Kamagi, D. H. dan Hansun, S., "Implementasi Data Mining dengan Algoritma C4.5 untuk Memprediksi Tingkat Kelulusan Mahasiswa," ULTIMATICS, vol. VI, no. 1, pp. 1520, 2014.

[8] Hastuti, K., “Analisis Komparasi Algoritma Klasifikasi Data Mining Untuk Prediksi Mahasiwa Non Aktif," Seminar Nasional Teknologi Informasi \& Komunikasi Terapan 2012, pp. 241-249, 2012.

[9] Pambudi, R.D dan Supianto, A. A., "Prediksi Kelulusan Mahasiswa Berdasarkan Kinerja Akademik Menggunakan Pendekatan Data Mining Pada Program Studi Sistem Informasi Fakultas Ilmu Komputer Universitas Brawijaya," Jurnal Pengembangan Teknologi Informasi dan Ilmu Komputer, vol. 3, no. 3, pp. 2194-2200, 2019.

[10] Acharya M. S., "Kaggle," [Online]. Available: https://www.kaggle.com/mohansachar ya/graduate-admissions. [Diakses 24 April 2020].

[11] "OpenML," [Online]. Available: https://www.openml.org/a/estimationprocedures/1. [Accessed 20 April 2020].

[12] Imandoust, S. B. and Bolandraftar, M., "Application of K-Nearest Neighbor (KNN) Approach for Predicting Economic Events: Theoretical Background," $S \quad B$ Imandoust et al. Int. Journal of Engineering Research and Applications, vol. 3, no. 5, 2013.

[13] Bramer, M., "Principles of data mining," Springer, 2007.

[14] Liem, A. T, Sandag, G. A. Hwang, I. $\mathrm{S}$ and Nikoukar, A., "Delay analysis of dynamic bandwidth allocation for triple-play-services in EPON," 2017.

[15] Sui B., "Information Gain Feature Selection Based On Feature Interactions," 2013. 